\title{
Interview
}

\section{Data warehousing and consumer analytics in the era of customer engagement - An interview with Bill Franks of Teradata}

\section{Bill Franks}

oversees an Advanced Business Analytics Practice at Teradata. His team helps Teradata's clients implement advanced analytics and data mining techniques to improve their business and gain value from their corporate data. His work has spanned clients in various industries ranging from Fortune 100 companies to small non-profit organizations. Bill defines advanced analytics and how they can help retailers compete in the current economic environment. He also shares how retailers can build analytic competency into their organizations and best leverage analytic solutions.

\section{ABSTRACT Teradata provides enterprise data warehousing to multinational corpora- tions. Bill Franks, a managing partner, discusses with Michael Moon innovations in the industry for data warehousing and statistical modeling.}

Journal of Digital Asset Management (2009) 5, 352-363. doi:10.1057/dam.2009.27

Keywords: analytics; marketing; customer; data warehousing; data mining; statistical modeling

MM: We're here with Bill Franks of Teradata. Bill - would you give us a little bit of your background professionally?

BF: Yes. My background has always been in what we term today Advanced Analytics, Data Mining and Statistical Modeling.

I have a Master's degree in Statistics and have spent the duration of my career in the consulting realm, helping clients leverage their data to generate business value. To me, the technical methods are irrelevant if they aren't being applied to solve an actual business problem.

MM: Give us a little bit of a background in terms of Teradata - where it has been, where it is today and where it's going.

BF: Teradata was built from day one to enable scalable analytics through parallel processing. Even back in the '80s, Teradata was the leader in breaking new ground with data. The underlying architecture really hasn't changed that much over time, though the performance and tools built upon it have obviously evolved massively.

Teradata enables you to store, join and analyze large data tables. With other database engines, you more or less end up going through tables row-by-row in one fashion or another. Teradata breaks the processing up into little chunks, which greatly improves performance.

We have clients that have crossed the petabyte level. We're now a standalone, publicly traded company that is part of the S\&P 500. Gartner Group consistently rates Teradata as the leader in the data warehousing space. MM: One of the ideas I'd like you to expand on is the notion of a massive parallel database processor. Is that similar to what blade computing is, today?

You could compute or do a query against a massive database. You could distribute that across 500, 1000 or 1500 of these individual processors. Has the concept evolved since then? BF: Yes. I think you have the general concept. Teradata has physically distinct disk and CPU components that the data is spread across. You actually have dedicated CPU and disk space managing each of the individualized chunks of that data.

We have a backbone called the 'Bynet', which is an incredibly high-speed connection between 
those chunks of data. As one result is completed, it can quickly be aggregated with others.

There's a lot of hardware and software technology behind how Teradata does it. That's our core intellectual property and the root of our value proposition.

MM: With that as a background, could you bring us up to speed on the historical overview of customer analytics?

BF: When I first started out, we were doing analysis against mainframe-based systems. There was a large tape repository that housed the data.

I remember having to call the data center now and then when there was a major deadline. You'd actually talk to a guy in the data center.

You'd ask him if he could get your tape pushed up in the queue to run faster.

Back then, we didn't have near the amount of data we do now. So let's start with what people did from a direct marketing and customer analytics perspective 15-20 years ago.

The primary data that was available at that time were household demographic files. We'd send off names and addresses, and we'd get back the estimated income and the number of children and other demographic pieces of data on the customers. That was pretty much all companies had to develop programs around.

Then it evolved to where you'd have what I'll call 'aggregated sales data'. You might have Recency, Frequency and Monetary Value (RFM) data. How much have they purchased, how recently, how often?

It was very aggregated. Even at that, it enabled a much more refined view of the customers than the demographics did. Because time and again, you can show that demographics really don't do a good job of predicting behavior. Certainly not when compared to actual past behaviors.

RFM took it up a notch. Maybe people weren't collecting, storing and querying all of the sales history, line-by-line or transaction-bytransaction. But they at least had some feel for customer behavior, and were able to start to improve response rates and improve programs from there.

MM: Before we go on there, let's just do a quick little sidebar on RFM, for those of the readers that may not be familiar with it. As I understand it, it's Recency, Frequency and Monetary value.
BF: Recency measures how recently a customer last interacted with you. When did they last place a phone call or make a deposit or make a purchase? That's often measured in days, weeks or months.

Frequency measures how often they've interacted with you. There'd be some time period over which you'd measure it. Let's say we're talking about a year. How many transactions did they have in that year?

Monetary value measures the total sales or margin generated by the same transactions mentioned above.

MM: Which is to say that the actual data would come from a production data system that was also a system of record. This was a financial system, where transactions were recorded and processed.

Which is to say they were highly unique silos of data, that oftentimes had unique data sets specific to that silo.

BF: Yes. I think one of the earliest forms of database used for business purposes was the marketing database. It was really a silo, where you were trying to pull together whatever you could on those customers. It was very commonly distinct from any other repositories, and was customized more or less exactly to what marketing needed.

I think that's the difference today with the evolution of enterprise data warehouses. You're able to do much more, now, from a marketing perspective. But you're doing it in an environment that is providing more than just that specific marketing functionality.

The same environment is also providing financial analysis, product analysis and employee analysis. All the analysis is done with data that's in the one centralized place.

MM: From the tradition of customer analytics, we started off with basic, household transactions. Then into these aggregated databases - where you had RFM analysis and so on. What was the next step?

BF: I think the next step was, starting perhaps 10 years ago, more and more organizations were able to get hold of the detailed history of what every customer had purchased.

In a retail example, they know the details of all 30 trips that I made to the grocery store in the past year. They can see every single line item that I purchased. They know exactly what 
I paid for each item, if I had a coupon or a discount, if I returned an item and so forth.

We now use that data to get deeper underneath what a customer is about, what their preferences are, what their discount sensitivity is.

I think where we're heading is towards getting further pieces of information that aren't necessarily tied directly to purchases. For example, web data can identify what you've looked at or browsed or put in a cart before abandoning it. That data can be compared to what you've actually purchased. It adds another order of magnitude to the amount of data that needs to be stored and analyzed.

You want to try to understand the patterns behind each customer's purchases, and the mindset behind those purchases.

MM: That begins to get into the idea of developing patterns of engagement. Such that as customers start initially interacting with a brand, they do so online. As a function of that, it oftentimes creates mountains and mountains of anonymous or unnamed user data.

At some point, they may identify themselves. The idea then is, is there a way to start correlating all this activity on a website with promotions and other sorts of things that are happening in my market. Market conditions, competitive environments and so on.

Is that a fair summarization?

BF: Yes. And I think all the things you just described are starting to be discussed and are getting some attention. The primary organizations I'm aware of that have really done more than think about it are some of the purely web-based businesses.

They by definition are much newer organizations that were built around technology, to begin with. They're comfortable with that data. I haven't seen as many mainstream companies that have really embraced that, yet.

We recently announced an appliance that's focused on a low number of users, but massive amounts of data - it starts at 50 terabytes and it can go up to 50 petabytes.

It's targeted for these data sources that are just so large. You're not going to have very many people looking at it at any point in time. You're not necessarily going to want to be doing stuff with it every day. But you might have specific queries that require it to be accessible.
So it's now becoming feasible to analyze these new, massive data sources that reach into the petabyte domain.

Until technology catches up with theory, from a practical perspective, some things really can't be done cost-effectively. Even though in theory, you know it would have a benefit. Today, many things that were just theory are becoming truly practical. Organizations are starting to do these analytics. And, the early adopters will reap huge rewards over the slower competition.

MM: Before we get out too far into web analytics and its convergence with the traditional database analytics, I'd like you to speak to CRM. Both tactical CRMs that a salesforce. com is using, and an operational CRM like a call center or teleservice operation uses.

How did that begin to change and expand the data sets?

BF: Prior to the emergence of CRM toolsets, when you talked about customer marketing and analytics, analysts would manually create mail lists using a tool like SAS or SPSS to crunch through the data.

Then CRM tools came into play, starting with campaign management and slowly expanding. They enable automation of at least common and basic rules, so that the more technically savvy marketing people can go out and they could pull their own lists without help.

I've seen, as well over time, a convergence. It used to be that the call center - the operational component - was viewed as a customer service touch point only. If someone calls with a complaint, you try to resolve it. It wasn't really considered part of the marketing stream or the sales environment, whatsoever.

Now, you're getting the customer data centralized, and these different systems are pulling data from it, so you might have your marketing analysis feed from that data warehouse to do your direct marketing, while that same data might be feeding the call center.

So when the agent picks up the phone, they're able to see your recent orders, what segment you belong to, and what your 'next best offer' is.

What's happening now is that companies are taking advantage of whatever channels are available to interact with their customers, and try to be more consistent in their communications. 
You can still tee up the same offer you might've offered me in a direct mail piece 12 years ago and send me a mail piece. However, not only can you now e-mail that to me or send it to my mobile phone, but you can have your call center person mention the offer: 'Hey - by the way - if you're interested in this product we've been discussing - are you aware that other people who bought this are also interested in Products B, C and D?'

So tactical CRM and operational CRM are converging. Even your operational-oriented people and systems can be an extension of the customer marketing analytics in terms of delivering offers and messages to customers.

MM: We started off with our basic household transaction database. Then we started aggregating it in terms of RFM. Then we started to see CRM, both in terms of campaign management and operational support.

Now we're beginning to start seeing that in terms of sales enablement. As well as multichannel engagement.

BF: I'll give you one of my very favorite examples from a few years back. It was a major airline who started to do analysis of when some of their better customers got bumped from a flight, had a lost bag, had a cancellation or another bad event.

This was a great combination of a customer service issue and marketing and sales coming together. They went and offered a free day-pass to the airline club. Those are sort of ubiquitous, today - I think - as a result of what this airline did.

The airline found that people were thrilled that they were given this free day-pass that was officially valued at US $\$ 50$. It costs very little for the airline to have someone walk into the club. The cost of a beer and a few peanuts.

The pass had a high perceived value to the customer, and a low cost to the airlines. But the icing on the cake was that they found that 25-30 per cent of the people who redeemed that one-day pass ended up later buying a club membership.

Not only did they address the customer service issue to somebody's expectations and beyond, but they turned it into a sale for a very desirable purchase from that customer.

MM: Another theme that we're then beginning to explore, here, Bill, is the notion that marketing is no longer just about price position, packaging and promotion. It's really about the integration of marketing with sales and service.

There's a new set of analytics that are beginning to emerge that really starts to illuminate what's going on in a customer relationship, as they move through this pre-sale transaction and post-sale relationship.

Ultimately, the question is, "What can we do to retain this customer relationship?'

BF: Right. And it's getting more real-time too. Back in the old days, it would take a week to pull a list, and then you'd send it to the mail house and they'd print that and drop it. Your lead-time was weeks ahead of a drop. Then you might not have the data to analyze how the drop did until weeks after that.

Now, we have many, many organizations that have transactions loaded in real-time. Within seconds of making a purchase at the store, or booking an airline ticket, that transaction is already in the database.

For example, if there were a promotion on let's say - chips and salsa - you could then start to monitor it, in near real-time. 'Is this promotion working? Or is it not?'

Similarly, we have clients starting to intervene in near real-time with customers. My favorite example of that is one of our large casino customers. They track what you're typically willing to gamble and lose on a given trip.

Let's say I just happen to be having really bad luck. The casino knows that I normally will only lose or spend about $\$ 500$ on my weekend visit. They see I've just had this horrible run of luck and that I'm already down $\$ 350$ or $\$ 400$ and it's barely the early evening on Friday.

They will have one of the hosts get an alert to come over and intervene to say, 'Hey - you know what? How would you like to go have a free buffet? Or how'd you like some tickets for a show tonight?'

They purposely pull the customer away from the losing streak, so that customer doesn't spend all they've got too quickly and end up having a bad trip. The casino doesn't want to risk the customer not coming back because they feel that they didn't get their money's worth.

Again, it's in almost real-time. The only way you can know when I'm near my limit is if you're actually tracking exactly what my status 
is up until that minute from all the bets that I've been placing. It's pretty powerful.

We've just distilled the notion of analysis-driven intervention where I've got data that says, 'I need to go do something with Bill right now. Otherwise, our relationship is at risk'.

MM: Right.

We can take that and extend that into a web environment, looking for that point in time where you begin to start exhibiting web behavior that is basically indicative of, 'Gee - this is not going to be a good experience for Bill'.

There could be a similar policy-managed intervention that was ready for a particular trigger event to occur - such that you get a coupon and an invitation for something. Or maybe even a live offer for help.

BF: One of the examples I use is that, most every company is going to have a dashboard of some type. It's going to say, 'Bad Event Number One through Bad Event Number Five. We're willing to accept 0.1 per cent. Week-to-date and today so far, we're below that 0.1 per cent. Everything's good, and we're green across all these metrics'.

The catch becomes that it is a highly aggregated view. What you need to find is, 'What about that one person who has had a number of bad events occur even in the midst of our overall success?'

Let's just take an airline for an example. What if I'm a guy that was on the single flight that got canceled today? You also lost my bag as part of that experience. And you also then couldn't get me on another flight until tomorrow. Then you find out that some other things happened. The call center hung up on me twice accidentally, I was sent to the wrong hotel, etc.

If you start to add it up, you realize that while your aggregate metrics are 'green' across the board, in reality, you have some individual customers that are having a really bad day. You've got to recognize that. There may not be very many of them at any point in time - but those are the kinds of experiences that they will remember. A few very bad experiences can ruin relationships even with your best customers.

MM: There's another dimension of this, which I'd like you to explore a little more deeply. That's the notion of an ideal customer.

I think every business has an ideal customer. A customer whose expectations line up with service delivery.
As a function of this, the ideal customer, and/or degrees of that ideal customer set, corresponds to the lifetime profitability of that particular customer or relationship.

Could you speak to some of your insights around how data can support the identification of these ideal customers? Or is that even a valid distinction?

BF: I might illustrate it by way of a couple of exceptions. Where someone you'd think to be a valuable customer is not.

We were doing some segmentation work for one of our large fashion retail customers. As part of that work, they provided to us the customer scores that they currently used, which were very simplistic.

We went in and were computing customer value, as well. I remember we came back and said, 'You know, there is one thing we can't figure out. Are you aware that 10 per cent of the customers you have in your very, very upper tier are returning 90 per cent or more of their merchandise?'

They said, 'No. What do you mean?' We said, 'Have you been using net sales or gross sales?' They said, 'We've been using gross sales'.

Well, that led to us providing a list for them. Here were people spending $\$ 2000$ a year and returning $\$ 1900$. Or there were cases of someone spending $\$ 2000$ a year and returning $\$ 2200$.

Now you've been classifying someone as a 'best customer' and showering them with deals - while they're stealing from you. In some cases, someone may truly come in and take home 15 outfits, and then return 14. Even if they're not trying to defraud you, certainly they are nowhere near the top end for you as a valued customer. In fact, they're actually much less valuable than someone who doesn't spend very much because of all the costs associated with the returns.

So you have to be careful about how you define customer value.

Back to the airline example - you could have a customer who is continuously buying full-fare seats with no change penalty. Those tickets are expensive.

What if that guy is continuously not showing up for the flight he's on and rebooking on another one? You could end up losing revenue because you're holding a seat. If he doesn't 
show and he comes in for the next flight 2

hours later ... . Maybe you've lost the opportunity to sell that seat on the first flight. Maybe he reschedules a couple of times using the same ticket. He is adding substantial costs that need to be accounted for.

Just because someone gives you a lot of money upfront, you have to look at how much of that you were able to keep and what you had to spend to retain that money.

If the customer skipped a flight with 20 empty seats, maybe there really was no pragmatic cost to it. If it was a flight that was otherwise full, and you could've sold someone a ticket in the last few days .... What was the value of that ticket that you missed? And what was the probability that you missed it? That's where it starts to get more complex.

MM: Right. So, let's summarize.

In your experience, how many organizations really understand - have good data - in terms of how many customers they have.

BF: That's an interesting can of worms you've opened. I would say most companies when asked would tell you with confidence how many customers they have. But then you dig underneath it, and what really counts as a customer?

MM: Exactly.

BF: Oftentimes I'll be told, 'I have 40 million customers on my database'. Then I find out, 'Well, 10 million are people who registered on the web for an e-mail, and never actually bought anything. Another 20 million have not purchased anything in the last 4 years'.

And so on and so forth. It sounds silly, but how do you define a customer?

MM: Exactly.

BF: I think there's not a very good job done in delineating what we might call an active, current, ongoing customer from somebody you just happen to have on file.

Maybe 2 years ago they were a good customer. But if they're not doing anything today, I don't think it's fair to count them as a customer in the same sense as someone who made a purchase today.

MM: It also seems to me that this is one of the big misconceptions of CRM systems. I think the $\mathrm{C}$ in the CRM system is often the illusion.

In my way of thinking, a customer is - in a consumer context - the household. Then the individual that bought stuff would be the buyer of that customer organization. The customer will always be a business. Then you have buyers and users of the product or service within that business.

At the end of the day, business expenditures are all in one form or another a use of treasury funds.

One of the misconceptions that, I think, analytics needs to wend its way through and resolve is the notion of, "What really is the canonical definition of a "customer?", And what does it mean to have a relationship with that customer?

Is that fair? If so, can you expand on that? BF: Yes. Honestly, we could go talk to 20 Teradata clients and ask, 'Is your customer an individual, a household or something else?' We're going to have a pretty good split in percentage of each answer.

Let's say in a loyalty program, is it the card, the person or the household? I see in many cases, our clients use multiples of those.

They'd have some things that they're going to give to the card or individual. Other things, they might do to the household. And it's not always clear.

If you are a grocery store, to make me an offer based on my total household spending is probably reasonably safe. Because you know it's my wife, my kids and me. Regardless of which of us bought it, we're probably buying it for the benefit of the family.

Now the opposite extreme of that is where the people in the casino world are notoriously paranoid about revealing any information whatsoever. They have so many instances of the husband or wife sneaking off for the weekend. Worse yet, maybe they show up with someone who's not the husband or wife.

The last thing you want to do is say, 'We were glad you and the Mrs. were here last weekend. We'd love to have you back', and the real Mrs. is the one who opens it up at home and she was not there last weekend ...

I think there are many cases where there's not necessarily an absolute right or wrong answer. Each organization really has to think through what a customer is to them. At what level can they act? And at what level do they want to make those customers act?

So it's back to - I think - what sounds like a trivial question: 'Who is your customer?' Again, I 
don't know. It is not standardized by definition, but I don't know that there can be a standard definition.

Who your customer is really depends on the context of what you're doing with those customers. MM: So inherently, then, you're talking about a core assumption of a business model. Every business will have a business model. One of the key facets of that business model is, 'What constitutes a customer?'

BF: That's right.

MM: That then cascades into a whole set of subsequent assumptions and practices around data collection and analysis.

BF: That's right.

MM: Back to the idea of a dashboard; isn't it true that the primary desired piece of data at a dashboard is, 'How many customers do I have?' And, 'What's their status?' What are some of the other common elements in a dashboard? BF: A lot of folks like to see the high-level summary of current promotions and how they are doing.

And, especially in a market like today, with the recession, to know what the average transaction size is compared to a year ago.

Let's say your business is down 10 per cent in total sales. To give two extreme examples on either end of the spectrum, it could be you've lost 10 per cent of your customer base completely and the other 90 per cent are spending exactly the same way. Or it could be that 100 per cent of your customers are spending 10 per cent less, but you haven't lost a single customer.

I would submit that the way you'd respond to that 10 per cent decrease in sales - both in the aggregate and on an individual customer basis - would vary greatly, depending on where in that continuum the facts told you that you were resting.

MM: Also now, with respect to the customer, what other things are giving your customers good value?

BF: One good value point has been getting offers and incentives to customers at the point they interact with an organization.

For years now, consumers have gotten coupons at the grocery store that spit out with your receipt and that have some offers on them. They always seem somewhat relevant, but in actuality, the way those offers were driven was that the manufacturers would pay to push them to you. So, Coke would pay so that if you bought Pepsi, you would get a coupon for Coke.

But now companies want to personalize these offers to each customer. Not based on what a manufacturer's paying, and not based on what the customer has in today's basket alone ... . But ... . What do we know about that customer over a long period of time? And what do we think they might need?'

One example .... We worked with a retailer on what we call a 'Pantry-Loading Model'. We actually went and identified the historical purchasing of toilet paper, and how much each household consumed on a weekly basis. Then you look at when they last purchased toilet paper and how much they bought. From there, you can easily predict when you think they'll run out.

When I'm checking out, if I don't have toilet paper, but you think I'm getting close to being in need of toilet paper, give me a reminder of that. That has a real opportunity to drive an incremental purchase. We have clients now delivering offers of this type.

Clients are starting to talk more, but haven't yet as much started the true use of some of the new channels.

I don't think people have become comfortable yet, but I think that's a huge opportunity over time to be giving offers to people on their mobile phones while they're walking through the store.

The downfall on that Point of Sale (POS) example is, you're at checkout already and you've finished shopping. What about getting the offer to me once you know I've entered your store? Now I get the offer while I'm pushing the cart through the aisle rather than while I'm leaving.

Our clients are also starting to talk about some of the new web communities and so forth. How do you go out onto a Facebook and drive business effectively in that environment? That is out on the cutting-edge side of the curve. I don't know that many companies have done a whole lot with it, yet. But I think there's potential there.

MM: Facebook has about 210 million people on it, right now. Current projections suggest that's going to be 1 billion in 5 years. Facebook is no longer just a social network. It's transcended 
the category and has now become a utility, in terms of how people live, work and play.

In particular, of this 210 million people on Facebook today, the research indicates that there are about 60 million people that go there 50 times a day. It's no longer a 'destination', in the traditional sense of the word. It's actually a home base.

It's kind of a flat world/round world paradigm shift.

So if Facebook is the place from which I come, it quite literally becomes a virtual frame through which I view and interact with others in the world.

One of the implications of that is that oftentimes, the first meaningful point of engagement with a consumer is going to be on Facebook. So the question is, "What is an authentic and sustainable and innovative way of engaging consumers in a social environment such as Facebook?' I think that's the big, open question. I think there's still a lot of scratching of heads and a lot of gnashing of teeth, in terms of how to make all that happen. But clearly, it's going to happen there. Right?

BF: Right.

MM: The next big innovation is from Google. Eric Schmidt recently called it 'persistent locationbased personal search'.

The idea is, if you've got an iPhone or some of these other smart phones that have both WiFi and a 3-G network, as you're walking down the street, Google knows where you are. As a function of that, it's running in the cloud.

So as I wander around, there's a kind of search-within-a-search, filtered by my location. The only thing that's really missing there is my personal criteria - in terms of what I'm interested in. Google will be able to infer some of that as a function of my historical searches. But increasingly, there will be services that will say, 'Michael Moon is 56 years old and drives this kind of car. He makes this kind of money. He's explicitly interested in fine wines, ethnic foods, live music, the best dry cleaner, et cetera, et cetera'.

So as I'm moving around, all of a sudden, the search application can say, 'Oh! Given that you're interested in fine wines and ethnic foods, here's something that fits that criteria. Would you like to hear about it?'

We're beginning to see the notion of Facebook as a social interface mashing up with a persistent location-based search of what in my immediate vicinity, as a resource, I would necessarily be attracted to.

BF: I think that's interesting.

It changes the whole game from paying $\$ 2$ million to have a series of 60-second ads that'll run on 10 million TVs at a set point in time. Instead, you're going to pay a small amount of money to target specific individuals within a certain distance of your location. Those that you know will actually have an interest in your location - at the moment that they're there.

You may end up making millions of those offers just the same over a period of time. It may cost you the same, but it's so much more in context with what that customer wants and when they want it. So it should have - in my opinion the potential for an order-of-magnitude increase in the response and long-term benefits from efforts like you described.

MM: As we begin to bring that notion of social interfaces to markets, vis-à-vis Facebook, the idea is that I'm more or less in real-time communication with my buddies, vis-à-vis Facebook and/or Twitter. Microblogging in real-time, filtered by my location.

It seems to me that the next big piece to really fall into place is how the local merchants get in the game. I'm just speculating here, but it seems to me that local merchants - be it the drycleaner or restaurants or the little convenience store .... .

It seems to me that that merchant or shopkeeper will start using things like Twitter.

The idea then is that things like Twitter, and other forms of microblogging, become de facto content-management, authoring and provisioning systems for these local merchants. They can then quite literally create content vis-à-vis the little Blackberry or iPhone. They can then put out promotions that are specific for the day, and consumed locally.

BF: Yes. I can see that.

MM: Then I think it comes down to being able to figure out how to throttle that in a city environment.

Say I'm walking down a street in New York City where there could literally be 1000 different businesses within even a quarter mile or a couple 100 yards of me.

I think you'd have to arrive at the agencymiddleman concept of somebody determining, 
so that not all thousand little businesses are throwing things at me. That would completely overwhelm me, and actually make it all but unusable to somebody being the intermediary. Saying, 'Okay. You 50 businesses all want to tell Bill something right now. You've all paid for the opportunity to be considered. And you'll pay me if I do offer it'.

But somebody has got to be the traffic cop; you might call it, to decide, 'Of those 50, what are the two I'm going to let Bill have right now?' BF: Right.

MM: You've described, I think, in terms of a business ecosystem, a next-generation engagement agency. Specifically, somebody with whom the consumer has a trusted relationship.

This agency becomes a trusted information intermediary and aggregator. A traffic cop for me - the consumer. It's somebody with whom I'm comfortable sharing a lot more personal information about who I am and what kinds of interventions I might be willing to accommodate by social space and location.

This agency then brokers my preferences to the larger market. Out of that, they get a cut for facilitating that introduction of Bill walking down 56th Street in New York City.

BF: Yes. It may be similar to how you sign up with an Internet Service Provider. 'Who's going to deliver my Internet?' Well, 'I'm going to sign up with agency ' $\mathrm{X}$ ' to deliver me my geocentric customized offers ...' '.

MM: If it's not Facebook, it's going to be a Facebook partner who becomes that aggregator of trusted information for engagement. That provides the consumer a meaningful way of stipulating and defining engagement preferences by social context, and even by location.

BF: I'll tell you something else .... .

Think about text mining, which is another big thing we're seeing companies get into. They're actually taking complaints, comments, maintenance data or other 'free form input' where there are either hand-written notes or verbal comments and parsing that into database tables.

This is another opportunity within an environment like Facebook. It gets a little 'BigBrotheresque' in some ways, so you'd have to be careful.

Let's say an automated analysis engine is looking at the conversations between four friends and myself that have been going back and forth. It notices the pattern of what we are talking about. That could lead to the proactive offer. For example, 'We should go to Myrtle Beach in May, sometime. Where might we stay?' A few more related comments could cause offers to be put forth to the group since the engine recognized a pattern of need in our dialogue.

Or, a conversation is along the lines of, 'We need a really good Indian restaurant, tonight. Why don't we meet up somewhere?' Then the analysis engine comes up with, 'If you're looking for an Indian restaurant and you're going to be in mid-town Atlanta, here are three places that our users have rated highly in the past'.

It's not just the preferences I tell you directly, but what you can infer from what I've said and done. You have to do it in a way that would not be intrusive and Big-Brother-like. Yet it could add tremendous value to be told, 'We've noticed this conversation theme. Here are some things that you could be interested in'.

MM: That gets right into a topic that I've been developing now for about a year. It's called, 'Voice of Customer Content Analytics'. It starts off with just the premise that you've stated.

You have a powerful tagging engine that goes through Facebook and these other very social networks, blogs and forums. It starts to semantically tag content as it relates to particular opportunities, conversations, trends, as well as things like sentiment - positive/negative/neutral. Then to start to summarize those, in terms of a dashboard. Something that's now being referred to as 'social media analytics', or 'social media monitoring'. Now we're talking about data that we can start using as event triggers for various policies that would - in fact - become the basis for sending out special invitations to those guys that want to go out to Myrtle Beach in May. BF: I think you have to tie back into the technology enablers. Where Teradata could fit into a scenario like this is ....

Think about the masses of data that we're talking about here. You have tens of millions of users, interacting dozens of times a day. You are not only trying to understand the details of my interactions, but how each of those specific interactions ties to the interactions that my friends have had. If there's a pattern amongst 
the interaction my friends and I have had with other interactions other friends have had, you start to get into a huge volume of data, and a massive amount of processing required.

I think it's one of those things where 5 years ago, it would've sounded great, but I'm not sure it would've been remotely feasible to go after it on a large scale. I'm certain that with today's technology, you could at least experiment with it, if not take it all the way. MM: I would imagine this would be a fairly common practice now in terms of taking just the audio streams that are coming from call centers - or some sort of online teleservice center - and doing some sort of automated speech-recognition or speech-to-text. Then we could start doing the very specific content analysis.

Do you know of clients that are doing that sort of thing? And what sort of things they've been learning?

BF: I do know many companies are doing what I call the 'parsing-and-tagging' of text.

For example, taking the comment field from a complaint and determining key facts about that complaint. For example, it was about his car, it dealt with his tire being flat, he was unhappy with the response time he saw from us.

Now whether they're getting that data by doing a speech-to-text translation first, I don't know. But I don't see why you couldn't do it. Once you've transcribed the speech, you can parse it just the same as if it had been written in the first place. It is just a matter of adding the speech-to-text product in place.

MM: I've seen that in the trade journals - like speech technology. Where they refer to speech analytics. They're simply doing pattern recognition on the audio file. Looking for specific emotionally laden words, and using that to trigger a subsequent analysis of what's going on with that particular client.

BF: Yes. I think all of that's a good thing. Back to the warehouse scenario - what better way to get a leading-edge indicator of trouble than to be going through the customer comments on a minute-by-minute or hourly basis? To identify, 'Wow! We just had a volume of calls spike on " $x$ "'. Whatever that ' $x$ ' is. And people are really mad about it.

Maybe people are complaining that one of the lines in the airport is long because multiple flights in that terminal were canceled in a short timeframe. You have extra staff in other parts of the airport you can immediately re-deploy to assist the location that has a big line.

Maybe you find out that you're getting complaints from a hotel property, and you find out that the manager and assistant manager both called in sick that day. You've got someone that's not appropriate manning the desk, and you've got to get some help in there.

There are a whole lot of scenarios for doing those kinds of things, to understand what's driving my interaction with you.

We're into the realm now where we're not just talking purchases and purchase history, like we started out with. Now you're talking about trying to understand all the reasons I interact with you - many of which don't involve a purchase, per se, at that moment in time.

MM: I was working with a client in Finland on this very subject.

They were in the process of launching a whole new capability for online bill presentment and payment for households that weren't necessarily inclined toward online bill presentment and payment, using the college kids to go back and provision out the service for their parents and grandparents, as a way of speeding up the overall transfer or conversion process.

In the course of that, we recommended that they would conduct 50 telephone interviews a month with individuals that are somewhere in the process of 'awareness, consideration, trial, adoption', of this conversion process.

Simply documenting the journey of the customer. Where they are, what they're doing, what they've done, what they get confused by, what worked and didn't work and what needs to be improved.

In the course of doing these interviews, they've transcribed them. They've put them into a special content database whereby they did the text mining. Then they summarized it up into a nice little graphic dashboard.

As a function of this, they developed some really uncanny insights. One of the things they discovered that they didn't expect to find was that as they were tracking this particular earlyadopter group, they had in fact put in a whole kind of policy-management/policy-feedback system. 
Such that they were getting meaningful, constructive insights across the entire footprint of the enterprise. B2B, consumer, industrial customers - as well as what specific impacts or particular effects the particular policies had on the perception of value, quality and satisfaction.

Unlike someone saying, 'I believe our customers need this', now we had this growing base of data. Specific keywords and phrases summarized up in terms of sentiment - positive, negative and neutral, as it relates to a very specific policy.

So this voice-of-customer content analytics turned out to be a far richer and deeper source of insights, in terms of what is working - as well as what can be improved. And, what new insights we could use to drive even higher levels of value and satisfaction.

So that we get even better service and a more sustainable competitive advantage.

MM: This would then come back and probably provide some of the kernels or insights to go into traditional customer analytics.

BF: It's good stuff. I'd love to see these ideas become commonplace. It would really be neat to one day soon see somebody that's actively doing all of the things that we've talked about, alongside each other.

It has the potential to totally change the customer experience, and make somebody the next zero-to-many-billion-dollar company overnight.

MM: It seems to me, Bill, that we've already suggested where we're likely to see these. We're likely to see these in companies that were born digital. Somebody that was - from the get-go in a live, interactive relationship that already produced data. Whose website is the primary point of contact and interaction.

Engagement tends to happen pre-sale and post-sale, and it's really about relationships.

Beyond that, I think it's really up to leadership to determine if we're really an analytically led company or if we're more of a design- or aesthetically led company.

Right?

BF: Right.

MM: Do you have any ideas or early hints, in terms of who might be an early breakout in terms of this pioneering of next-practice?

BF: I'd hate to say any specific names. But I think I agree with your assessment. I don't know that it would be that possible for a 'legacy' organization that's been around for a while to break through on these things.

To your point, it's more likely to be a company that started out digitally, that is, a company that had data from the very beginning.

There might be an argument that some of the companies that we think of as fairly new companies - that started out digitally and that were using data and technology from the get-go ... that they came into being in the context of what was available at that point in time when they started.

Will it have to be a new company that comes in, taking some of these new things we've discussed for granted, the way the current pioneers took the digital aspects for granted? Some of the current cutting-edge companies may already be in the 'outdated' or 'legacy' digital mode, if there is such a thing. Maybe they are already too set in their ways. Some upstart will need to come in and change the game.

MM: If there were a new category of not bornnative but 'born-networked' company ... . It seems to me that part of their DNA would be they have a digital business model and a robust, nuanced multi-dimensional customer data model. Specifically, 'What is a customer? What does it mean to relate it? How do we compute or model future free cash flows from a base of one version of the customer truth?'

We recognize the inherent limitation of CRM as collecting a bunch of incomplete and incorrect data that - at some point - someone has to correct.

Why don't we collect the right piece of data once, and manage it holistically?

BF: Yes. I think another point is that most companies still think of themselves as pushing a product. If you went after these data-driven, customer-oriented strategies we're talking about, it becomes a lot less of a blatant sale.

It's like the friend over your shoulder saying, 'Hey - did you think about this?' It's much more discrete and suggestive in terms of guiding you in a direction - but not throwing in front of your face, 'Buy this thing now!'

It changes the entire sales approach and relationship. It would be a different way of looking at it and managing it.

MM: We're talking about a completely different mindset. Moving beyond the buyer/seller 
relationship, now toward evolving into a trusted producer or trusted partner, with a stakeholder.

So the customer is no longer just a buyer or a customer - but a stakeholder in this enterprise. One that continues to drive innovation and value into the customer base and market. BF: That's right.

MM: That's a great place, perhaps, to begin to summarize, here. The trend in analytics is really about two dimensions of transformation. One dimension of transformation is about how customers evolve into stakeholders in the organization. The other is how vendors evolve into really becoming trusted partners of customers.

Like you say - a 'known and trusted friend', who says, 'Hey! You might want to check this thing out'.

It kind of gets to some of the more lifestyle brands that you see. Quicksilver for the surfing set. Or Van's Shoes for the skateboarding set.
Individuals or companies that are more committed to a lifestyle than necessarily getting something sold today.

BF: Right.

MM: Well, Bill, I want to thank you so much. I think we're getting to about the end of our nickel, here. Any last comments in terms of our conversation today?

BF: I'll just say thanks for the opportunity to chat with you. As a guy who grew up doing analytics, I think these are fascinating topics. There are going to be people out there in the coming years that are going to have a lot of fun and make a lot of money figuring out how to make these things work.

The tools and skills are out there. Hopefully I'll get the opportunity at some point to get involved in some of these things firsthand myself.

MM: Absolutely. 